\title{
ГЕОМЕХАНИЧЕСКАЯ ОЦЕНКА РАЗВИТИЯ ЗОН ТЕХНОГЕННОЙ ТРЕЩИНОВАТОСТИ В НАДСОЛЯНОЙ ТОЛЩЕ НА АВАРИЙНОМ УЧАСТКЕ РУДНИКА СКРУ-2
}

\author{
С.Ю. Девятков \\ Горный институт УрО РАН, г. Пермь
}

\begin{abstract}
Аннотация: Рассмотрена ситуация на аварийном участке рудника СКРУ-2, где через 20 лет после массового обрушения междукамерных целиков произошло образование провалов на земной поверхности. Средствами математического моделирования исследовано состояние породного массива. На основе критериальной оценки состояния массива локализованы зоны техногенной трещиноватости пород надсоляной толщи. Установлены сквозные области нарушенности в интервале надсоляной толще.
\end{abstract}

Ключевые слова: провал, надсоляная толща, напряженно-деформированное состояние, разрушение надсоляной толщи, трещиноватость, математическое моделирование.

\section{Введение}

В 1995 г. в результате массового разрушения междукамерных целиков и обрушения кровли рабочих пластов на площади $600 \times 600$ м в северо-восточной части шахтного поля рудника СКРУ-2 сформировалась обширная мульда сдвижения с размерами в плане $650 \times 850$ м и максимальными оседаниями земной поверхности до 4,5 м [1]. В последующем наблюдалось дальнейшее увеличение оседаний в пределах зоны обрушения.

Обзорная схема района зоны обрушения представлена на рис. 1. Данная территория в геологическом отношении характеризуется достаточно сложными условиями залегания пластов. Глубина залегания отрабатываемых сильвинитовых пластов варьируется в широком диапазоне (например, по кровле пласта КрII от 240 до 360 м). На исследуемом участке отрабатывались три пласта (АБ, КрІІ и Вс) в различных сочетаниях.

В рамках комплексного сейсмогеомеханического мониторинга аварийного участка, начиная с 1996 г. в его пределах и на прилегающих территориях проводятся режимные сейсморазведочные наблюдения по сети наземных и шахтных профилей. В процессе этих работ выделен ряд сейсмических аномалий, характеризуемых нарушением волновой картины, изменением кинематических и динамических характеристик упругих волн. По результатам геофизической и геомеханической интерпретации данные аномалии связаны с формированием в результате деформирования подработанного массива техногенных ослабленных зон с пониженными механическими свойствами.

Согласно результатам выполненных исследований, аномалии были объединены и выделена обширная область максимальных негативных изменений, пересекающая зону обрушения с северо-запада на юго-восток, с двумя эпицентрами на границах зоны обрушения. Пространственное положение аномалий на текущий момент времени показано на рис. 1.

В сентябре 2014 г. на исследуемом участке было зафиксировано резкое увеличение сейсмической активности в районе юго-восточной границы зоны обрушения, а в ноябре - поступление надсолевых вод в горные выработке. 18 ноября был обнаружен провал на земной поверхности, размеры которого составили в коренных породах - 25x54 м, а в рыхлых отложениях на уровне земной поверхности - 50x80 м. Место провала на плане указано на рис. 1.

В дальнейшем наблюдалось увеличение размеров провала в плане преимущественно в северном направление, а 2 мая 2018 г. северо-западнее провала 2014 г. произошло образование еще одной воронки с размерами $25 \times 30$ м. Положение и размеры контуров воронок на настоящий момент времени показаны на рис. 1. 


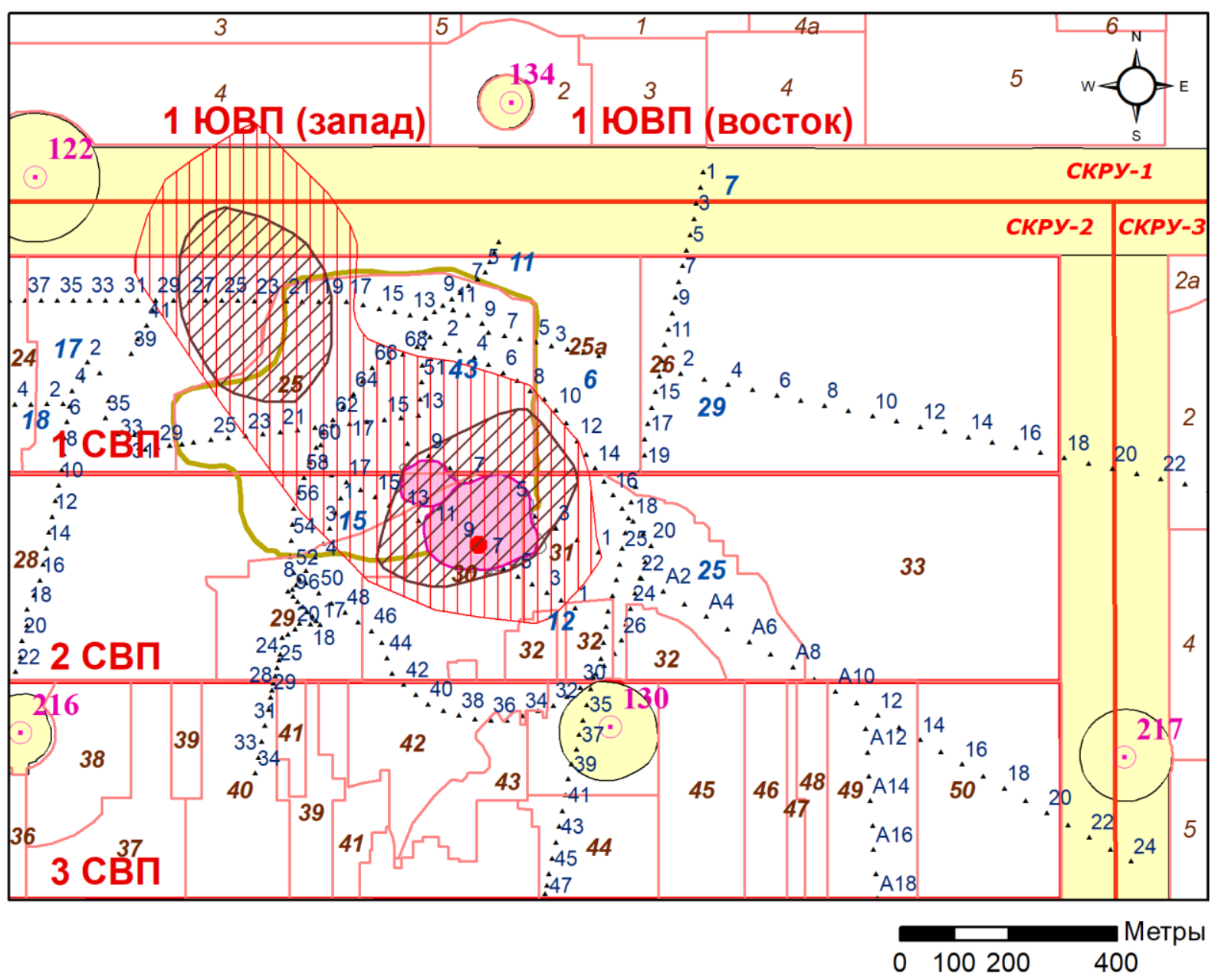

\section{Условные обозначения}

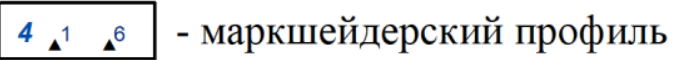
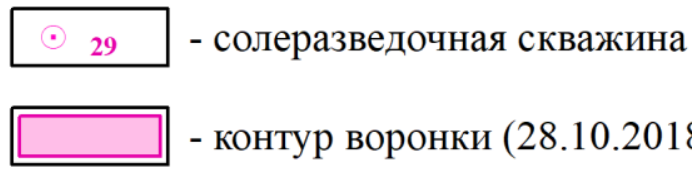

- контур воронки (28.10.2018)

- зона максимальных негативных

изменений (по данным сейсморазведки)

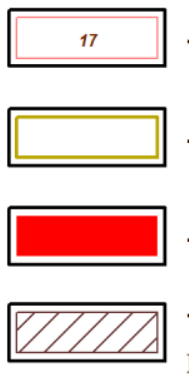

- панели, блоки, зоны

- зона обрушения

- провал 18.11.2014

- эпицентр максимальных

негативных изменений

Рис. 1. Обзорная схема района исследований

Целью настоящих геомеханических исследований является оценка методами многовариантного математического моделирования пространственного положения зон техногенной трещиноватости пород, сформировавшихся на аварийном участке в интервале надсоляной толщи, определяющих интенсивность гидрофильтрационных процессов. Стоит отметить, что активное развитие фильтрационных и суффозионно-карстовых процессов в надсоляной толще способствует формированию крупных карстовых пустот, над которыми происходят провалы [2].

\section{Постановка задачи}

Математическое моделирование НДС подработанного массива на исследуемом участке проводилось в трехмерной постановке. 
Выработанное пространство моделировалось средой с пониженными по отношению к породам соответствующего пласта свойствами. Степень уменьшения механических свойств определялась параметрами камерной системы разработки. На отработанных площадях в расчет принимались фактические значения реализованных параметров.

Математическое моделирование состояния породного массива выполнялось в упругопластической постановке с учетом всего комплекса горно-геологических (особенности строения, гипсометрия пластов и др.) и горнотехнических (количество отработанных пластов, параметры системы разработки, порядок отработки, наличие закладки выработанного пространства и т.д.) факторов. Граничные условия формулировались из следующих соображений: верхняя граница (земная поверхность) принималась свободной; выбранные размеры исследуемой области обеспечивали равенство нулю на нижней границе вертикальных, а на боковых - горизонтальных перемещений.

Для анализа деформирования подработанного массива во времени использовался реологический подход, основанный на математическом описании графиков нарастания оседаний земной поверхности [3], для реализации которого предложена модификация известного метода переменных модулей упругости [4]. Согласно ей переменными во времени модулями описывается деформирование не всех элементов геологического разреза, а лишь отработанных пластов. Преимущество этой модификации заключается в том, что она позволяет раздельно описать временной характер деформирования всех отработанных пластов, легко учесть разницу в сроках их отработки и оценить состояние подработанного массива на произвольный момент времени.

Локализация пластических деформаций в физическом смысле трактовалась, как разрушение пород массива: в области сжатия вследствие развития трещин сдвига, в области растяжения - трещин отрыва. В свою очередь, выделенные по результатам сейсморазведочных работ аномалии локализуют в пространстве зоны, отражающие снижение механических свойств пород за счет техногенной трещиноватости. Данное соответствие позволяет производить настройку геомеханической модели по данным сейсморазведочных наблюдений. Её суть заключается в подборе таких прочностных характеристик пород, которые обеспечивают пространственное согласование зон пластических деформаций и установленных геофизических аномалий.

Для идеальной упругопластической среды связь между деформациями и напряжениями на допредельной стадии подчиняется закону Гука, а предельные напряжения в области сжатия определяются критерием Кулона-Мора. Паспорт прочности соляных пород описывается параболической огибающей кругов Мора [5], построенной по известным значениям их пределов прочности на растяжение $\left(\sigma_{r}\right)$ и сжатие $\left(\sigma_{s}\right)$.

Специфика поведения горных пород в поле сжимающих напряжений состоит в том, что пластическое деформирование в них осуществляется за счёт образования трещин сдвига. Таким образом условием разрушения соляного массива за счёт образования трещин сдвига является выполнение неравенства:

$$
K_{k}=\frac{\tau_{\max }}{\tau_{p r}}=\frac{\tau_{\max }}{\sqrt{\left(\sigma_{r}+\sigma_{n}\right)\left[2 \sigma_{r}-2 \sqrt{\sigma_{r}\left(\sigma_{r}+\sigma_{s}\right)}+\sigma_{s}\right]}} \geq 1 .
$$

При этом касательное $\left(\tau_{\max }\right)$ и нормальное $\left(\sigma_{n}\right)$ напряжения определяются на площадках, где отношение $\tau_{\max } / \tau_{p r}$ достигает максимального значения.

В области растяжения предельное напряжение ограничивается пределом прочности на растяжение:

$$
\sigma_{1}=\sigma_{r}
$$


При вычислении значения предельного касательного напряжения $\tau_{p r}$ должна учитываться зависимость прочностных параметров соляных пород (пределов прочности на одноосное растяжение и сжатие) от времени, посредством введения в расчёт коэффициента длительной прочности, определённого по результатам реологических испытаний [6].

Численная реализация трехмерного математического моделирования осуществлялась в соответствии с полуаналитической схемой метода конечных элементов, включающей разложение вектора смещений в ряд Фурье по горизонтальной пространственной координате [7]. Решение упругопластической задачи основывалось на методе начальных напряжений $[8,9]$.

\section{Локализация зон техногенной трещиноватости пород надсоляной толщи}

Анализ НДС подработанного массива на аварийном участке выполнялся на 2019 г.

На рис. 2 и 3 приведено распределение областей техногенной нарушенности по сечениям в интервале надсоляной толщи и вертикальным разрезам соответственно.

В нижней части СМТ (рис. 2, а) отмечается небольшая область трещиноватости между северной границей зоны обрушения и барьерным целиком, в верхней части (рис. 2, б) - более протяженная по латерали на этом же участке, а также вдоль восточной границы зоны обрушения. По обоим сечениям в СМТ происходит формирование областей нарушенности в районе контура воронки.
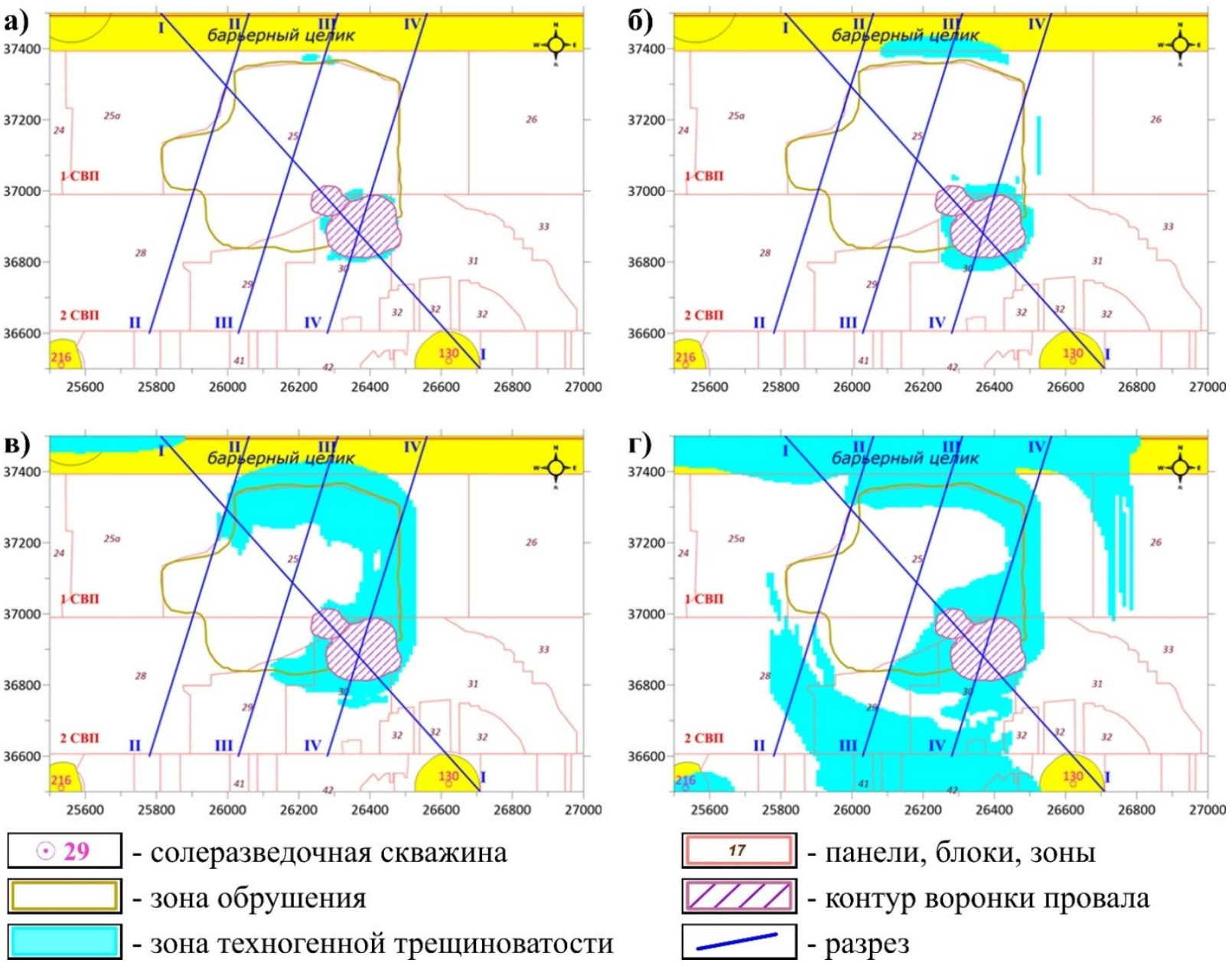

Рис. 2. Распределение зон техногенной трещиноватости в нижней (а) и верхней (б) части СМТ, в нижней (в) и верхней (г) части ТКТ 
По всем разрезам (рис. 3) сквозные области техногенной нарушенности в СМТ фиксируются только по контуру воронки провала. При этом следует обратить внимание, что в районе барьерного целика по разрезу III-III (рис. 3, в) происходит формирование обширных направленных друг к другу субвертикальных областей нарушенности в верхней и нижней части СМТ, которые при развитии процесса сдвижения могут образовать сквозную область техногенной трещиноватости.
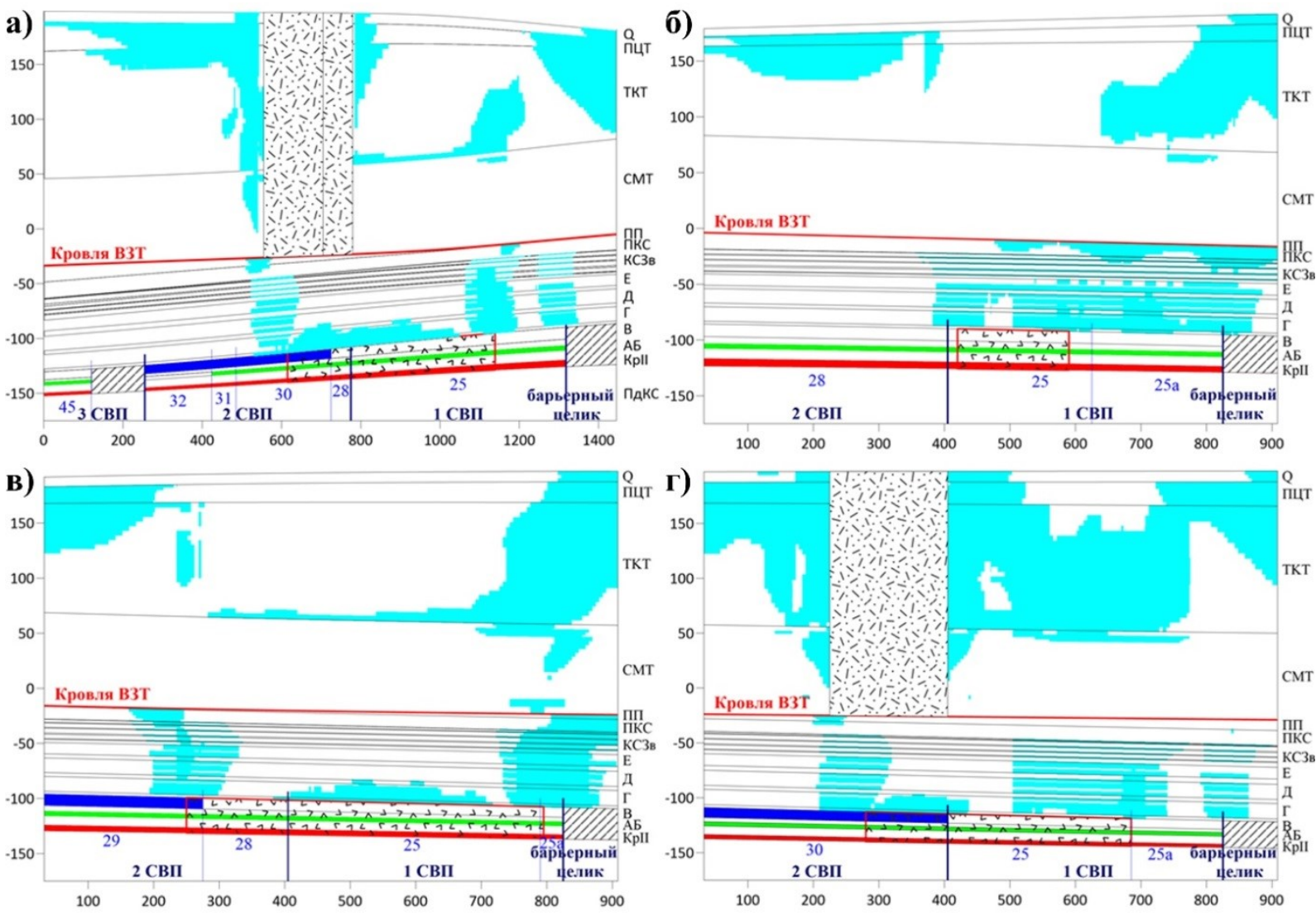

- зона обрушения

- зона техногенной трещиноватости

- провал на земной поверхности

Рис. 3. Распределение зон техногенной трещиноватости по разрезам I-I (а), II-II (б), III-III (в), IV-IV (г)

В ТКТ области техногенной нарушенности имеют существенно большие размеры: в нижней части ТКТ (рис. 2, в) трещиноватость охватывает все границы зоны обрушения за исключением юго-западной, в верхней (рис. 2 , г) - разрушения отмечаются на барьерном целике, северной и восточной границах зоны обрушения, а также фиксируется обширная область трещиноватости в южной части исследуемого участка, подходящая к зоне обрушения с юго-запада.

По разрезам (рис. 3) можно отметить, что сквозные области техногенной трещиноватости в ТКТ, наряду с районом провала, образуются также на барьерном целике.

Таким образом, критериальные оценки состояния надсоляной толщи на аварийном участке показывают, что к 2019 г. происходят обширные сквозные разрушения ТКТ в районе барьерного целика и восточной границы зоны обрушения, которые оказываются соединёнными с воронкой провала на земной поверхности. При этом у барьерного целика также развиваются зоны трещиноватости в верхней части СМТ, что может приве- 
сти к образованию здесь сквозной области техногенной нарушенности в надсоляной толще.

\title{
Выводы
}

Геомеханический анализ состояния породного массива на аварийном участке шахтного поля рудника СКРУ-2 показывает, что в интервале надсоляной толщи области техногенной трещиноватости приурочены к краевым частям зоны обрушения 1995 г. т.е. к участкам высоких градиентов мульды сдвижения. При этом можно отметить, что в отличии от СМТ, где фиксируются локальные зоны техногенной нарушенности, в ТКТ образуется сплошная область техногенной трещиноватости от барьерного целика до района провала и далее вдоль южной границы зоны обрушения. В районе барьерного целика разрушению оказывается подвержена вся надсоляная толща за исключением лишь центральной части СМТ.

Вследствие того, что техногенная трещиноватость оказывает влияние на фильтрационные свойства пород, увеличивая скорость фильтрации, возможно повышение интенсивности гидрофильтрационных процессов в интервале надсоляной толщи вдоль границ зоны обрушения по направлению к району провала.

\section{Работа выполнена в рамках госзадания № 0422-2019-0148-С-01.}

\section{БИБЛИОГРАФИЧЕСКИЙ СПИСОК}

1. Барях А.А., Санфиров И.А., Еремина Н.А., Бабкин А.И., Сабиров Р.Х., Гилев М.В., Мынка Ю.В. Контроль за развитием аварийных ситуаций на калийных рудниках // Горн. вестн. - 1997. - №6. - С. 91-101.

2. Осипов В.И., Барях А.А., Санфиров И.А., Мамаев Ю.А, Ястребов А.А. Карстовая опасность при затоплении калийного рудника в г. Березники Пермского края Российской Федерации // Геоэкология. 2014. - № 4. - С. 356-361.

3. Амусин Б.З. Об использовании переменных модулей при решении одного класса задач линейнонаследственной ползучести // Изв. АН СССР. Механика твердого тела. - 1974. - № 6. - С. 162-166.

4. Барях А.А., Самоделкина Н.А. Об одном подходе к реологическому анализу геомеханических процессов // Физико-технические проблемы разработки полезных ископаемых. - 2005. - №6. - С. 32-41.

5. Кузнецов Г.Н. Механические свойства горных пород. - М.: Углетехиздат. - 1947. - 180 с.

6. Барях А.А, Асанов В.А., Паньков И.Л. Физико-механические свойства соляных пород Верхнекамского калийного месторождения: учеб. пособие. - Пермь: Изд-во ПГТУ, 2008. - 198 с.

7. Зенкевич О. Метод конечных элементов в технике. - М.: Мир, 1975. - 541 с.: ил.

8. Малинин Н.Н. Прикладная теория пластичности и ползучести. - М.: Машиностроение, 1975. - 400 с.

9. Фадеев А.Б. Метод конечных элементов в геомеханике. - М.: Недра, 1987. - 221 с.: ил.

\section{ОПРЕДЕЛЕНИЕ ВЕЛИЧИНЫ ЛИНИИ НАИМЕНЫШЕГО СОПРОТИВЛЕНИЯ ШПУРОВОГО ЗАРЯДА ВВ С УЧЁТОМ ЕГО РАДИАЛЬНОГО ЗАЗОРА}

\author{
В.М. Мальцев, В.В. Аникин \\ Горный институт УрО РАН, г. Пермь
}

\begin{abstract}
Аннотация: Рассмотрено воздействие взрывного импульса шпурового заряда на процесс дробления горных пород с учетом радиального зазора и показана возможность расчёта величины линии наименьшего сопротивления заряда ВВ с заданной степенью дробления взорванной горной массы для любого типа горных пород с учетом их прочности.

Ключевые слова: импульс взрыва, давление, длительность импульса, степень дробления, радиус, шпуровой заряд, радиальный зазор.
\end{abstract}

